\title{
Postarthroscopy Osteonecrosis of the Knee: Current Concepts
}

\author{
Francesco Di Caprio ${ }^{1}$ Renato Meringolo ${ }^{1}$ Maria Adiletta Navarra ${ }^{1}$ Massimiliano Mosca ${ }^{2}$ \\ Lorenzo Ponziani ${ }^{1}$ \\ 1 Operating Unit of Orthopedics and Traumatology, AUSL of Romagna, \\ Ceccarini Hospital, Riccione, Italy \\ 2 Second Orthopedics and Traumatology Clinic, Rizzoli Orthopedic \\ Institute, Bologna, Italy \\ Address for correspondence Francesco Di Caprio, MD, U.O. \\ Ortopedia e Traumatologia, Ospedale Ceccarini, Viale Frosinone, \\ Riccione 47838, Italy (e-mail: fra.dicaprio@gmail.com).
}

Joints 2017;5:229-236.

\begin{abstract}
Keywords

- osteonecrosis

- knee

- arthroscopy

- meniscectomy

- treatment

Knee osteonecrosis is a severe disease rapidly leading to end-stage osteoarthritis, which was classified into three categories: spontaneous, secondary, and postarthroscopy. To understand postarthroscopy osteonecrosis of the knee, all the three types of knee osteonecrosis have to be deepened. This article reviewed spontaneous and secondary osteonecroses of the knee, with special focus upon postarthroscopy osteonecrosis, which is a rare form, affecting patients operated for arthroscopic knee surgery, most commonly for meniscectomy. Due to its rarity, patients and surgeons are often unprepared for this complication. A correct diagnosis is essential for appropriate treatment, and also to determine if a preexisting osteonecrosis was present, avoiding medicolegal sequelae, although many authors agree that osteonecrosis (both spontaneous and postarthroscopy) represent unpreventable and unpredictable conditions. In spontaneous osteonecrosis, the treatment is defined according to the size and the degree of the lesion, whereas in postarthroscopy osteonecrosis, the size of the lesion has no prognostic value, and therefore, the choice of the correct treatment is based more on the timing of the diagnosis. A diagnostic and therapeutic algorithm was outlined on the basis of the actual knowledge.
\end{abstract}

\section{Introduction}

Osteonecrosis of the knee is a severe disease rapidly leading to end-stage osteoarthritis, which was first described by Ahlbäck et al in $1968 .^{1}$ The knee is the second most common affected site after the hip. ${ }^{2}$

Knee osteonecrosis was later delineated into three categories: spontaneous, secondary, and postarthroscopy. A good knowledge of the first two is essential to understand the third, which is the most rare and unexpected form. Many arthroscopic surgeons in fact are not aware of its existence until a case does occur.

Spontaneous osteonecrosis of the knee (SPONK) (also called primary osteonecrosis) is the most common type, with an incidence of $3.4 \%$ in patients older than 50 years and $9.4 \%$ in patients older than 65 years. $^{3}$

Secondary osteonecrosis affects more commonly younger patients, frequently have multiple and bilateral locations, and is associated with recognized conditions, such as alcohol abuse, corticosteroids, tobacco, sickle cell disease, and myeloproliferative disorders.

Postarthroscopy osteonecrosis is the rarest form, affecting patients operated for arthroscopic knee surgery, most commonly for meniscectomy.

This article reviewed the three types of knee osteonecrosis, summarizing the actual knowledge about demographics, etiology, diagnosis, and treatment. Special focus was made upon postarthroscopy osteonecrosis, delineating risk factors, differential diagnosis, medicolegal implications, and treatment.

\section{Spontaneous Osteonecrosis of the Knee}

SPONK is most common in patients older than 65 years, with a male-to-female ratio of $1: 5,{ }^{3}$ and is typically unilateral. ${ }^{4}$ The medial femoral condyle is affected in $94 \%$ of the cases. ${ }^{5}$ Its real prevalence may be underestimated because many published online

November 6, 2017
DOI https://doi.org/

10.1055/s-0037-1608666. ISSN 2282-4324.
Copyright (c) 2017 Georg Thieme Verlag License terms KG Stuttgart · New York 
cases of end-stage osteoarthritis could be due to occult osteonecrosis. $^{6}$

Vascular and mechanical factors are involved. While a vascular etiology continues to be the dominant theory for osteonecrosis of the femoral head, these predisposing factors have yet to be consistently demonstrated in patients with SPONK. Nevertheless, a cadaveric study demonstrated limited vascular supply to the medial femoral condyle compared with the lateral. ${ }^{7}$

Recent studies suggested subchondral insufficiency fractures in osteopenic bone, leading to synovial fluid accumulation in the bone marrow, with subsequent edema, focal ischemia, and osteonecrosis. ${ }^{8}$ An association was demonstrated between low bone mineral density and the incidence of SPONK in women more than 60 years of age. ${ }^{9}$

Case series have identified medial meniscal tears in 50 to $78 \%$ of patients with SPONK. ${ }^{10-12}$ In elderly patients with osteoporotic bone, discontinuity of the medial meniscus results in loss of hoop stress distribution in the medial compartment, thus increasing the load experienced in the femoral condyle and potentially predisposing patients to the development of subchondral insufficiency fracture.

Patients with SPONK usually present with acute onset of medial knee pain, just proximal to the joint line. X-rays are usually negative. ${ }^{13}$ Magnetic resonance imaging (MRI) is recommended for the diagnosis. ${ }^{14}$

SPONK is commonly classified in four stages following the Koshino et al classification: ${ }^{15}$ (1) knee symptoms with normal radiographic finding, (2) flattening in the weightbearing area and subchondral radiolucency surrounded by osteosclerosis, (3) extended radiolucency and subchondral collapse, and (4) osteoarthritis.

The Ficat classification ${ }^{16}$, originally described for femoral head osteonecrosis, includes four stages based on joint space narrowing, subchondral collapse, and trabecular pattern: (1) knee symptoms with normal radiographic findings, (2) sclerosis or cysts with normal joint line, (3) normal or slightly narrowed joint space with subchondral collapse and a sequestered appearance of the trabeculae ("crescent sign"), and (4) joint space narrowing and subchondral collapse.
The size of the lesion measured upon X-rays in case of SPONK represents a prognostic factor and gives indication for treatment, as lesions $<3.5 \mathrm{~cm}^{2}$ usually regress with nonsurgical management, lesions sizing 3.5 to $5.0 \mathrm{~cm}^{2}$ may or may not regress, while large lesions $>5 \mathrm{~cm}^{2}$ usually lead to condyle collapse. 6,17

Based on these findings, a treatment protocol for SPONK is summarized in - Fig. 1.

\section{Secondary Osteonecrosis of the Knee}

Secondary osteonecrosis of the knee (SONK) usually affects patients younger than 45 years, frequently with multiple lesions in multiple joints. SONK preferably affects women and hip joints, and is bilateral in $80 \%$ of cases. ${ }^{2}$

Corticosteroid and alcohol abuse are the most common risk factors, being involved in $90 \%$ of cases. ${ }^{2}$ Other risk factors include tobacco, sickle cell disease, Caisson's disease, and coagulopathies are responsible of vaso-occlusive effects (-Table 1).

In contrast to SPONK, SONK usually presents with gradual onset of pain. Pain may be located in multiple joints, and the knee may be affected in various sites. Similarly to SPONK, MRI is the recommended exam, while X-rays are often negative.

Secondary osteonecrosis showed different outcomes; in fact, symptomatic patients will almost uniformly need surgery. Therefore, nonsurgical management is recommended only for those patients who are asymptomatic. ${ }^{2}$ It was found that only $19 \%$ of the symptomatic patients had satisfactory outcomes when managed nonoperatively, while $70 \%$ went on to eventually require total knee arthroplasty (TKA). Asymptomatic lesions treated nonoperatively were successful in $80 \%$, avoiding arthroplasty and with no radiographic progression.

\section{Postarthroscopy Osteonecrosis of the Knee}

This condition was first described by Brahme et al in $1991 .^{18}$ Later, it was referred as "postarthroscopy,"19 "postmeniscectomy,"20-22 or "osteonecrosis in the postoperative knee" $(\mathrm{ONPK}){ }^{23}$

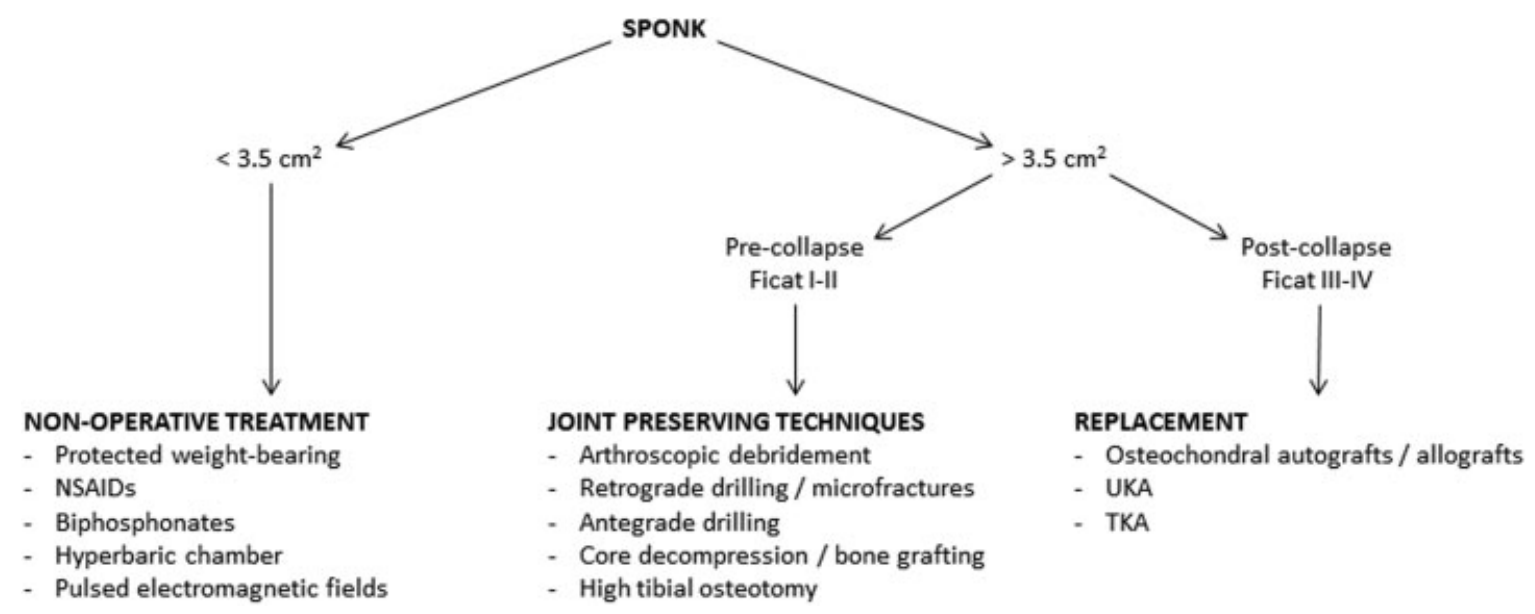

Fig. 1 Treatment algorithm for SPONK. NSAIDS, nonsteroidal anti-inflammatory drugs; SPONK, spontaneous osteonecrosis of the knee; TKA, total knee arthroplasty; UKA, unicompartmental knee arthroplasty. 
Table 1 Secondary causes of osteonecrosis

\begin{tabular}{|l|}
\hline Alcoholism \\
\hline Coagulopathies \\
\hline Caisson's disease \\
\hline Chemotherapy \\
\hline Corticosteroids \\
\hline Cushing's syndrome \\
\hline Diabetes \\
\hline Familial thrombophilia \\
\hline Gaucher's disease \\
\hline Gout \\
\hline Hyperlipidemia \\
\hline Inflammatory bowel disease \\
\hline Liver disease \\
\hline Organ transplantation \\
\hline Pancreatitis \\
\hline Pregnancy \\
\hline Radiation \\
\hline Renal disease \\
\hline Sickle cell disease (and other hemoglobinopathies) \\
\hline Smoking \\
\hline $\begin{array}{l}\text { Systemic lupus erythematosus (and other connective tissue } \\
\text { disorders) }\end{array}$ \\
\hline Tumors \\
\hline
\end{tabular}

Considering the high number of arthroscopic meniscectomies worldwide performed, the prevalence of ONPK seems to be very low. Santori et $\mathrm{al}^{24}$ reported that of more than 2,000 knee arthroscopies performed at their hospital over 10 years, there were only two documented cases of osteonecrosis $(0.2 \%)$ that occurred early, and mentioned that other cases could have been misdiagnosed. Pruès-Latour et $\mathrm{al}^{25}$ reported nine cases among 585 arthroscopic meniscectomies on patients older than 50 years (1.5\%).

A wide review published in 2007 by Pape et al $^{23}$ collected 47 cases of ONPK described in the literature after arthroscopic meniscectomy. The cited review did not consider the use of radiofrequencies (RFs) or laser procedures, in which thermal or photoacoustic effects could play a role.

Men and women were equally affected by ONPK after arthroscopic meniscectomy, with a mean age of 58 years. ${ }^{23}$ This was in contrast with SPONK, which affects predominantly elderly females.

Of the 47 cases, 41 had a medial meniscus tear (87\%) and 6 a lateral (13\%). The medial femoral condyle was affected in 39 cases (83\%), the lateral femoral condyle in $4(8.5 \%)$, the lateral tibial plateau in 2 (4.3\%), and the medial tibial plateau in 2 (4.3\%). The affected area always coincided with the site of the arthroscopic procedure. ${ }^{23}$ Sixty-five percent of the cases had a preexisting chondral lesion of varying degree.
The etiology of ONPK is debated. Altered knee biomechanics after meniscectomy may be a predisposing factor for osteonecrosis. $^{26}$ Increased tibiofemoral contact pressure might result in insufficiency fracture of the cartilage and subchondral bone with an intraosseous leak of synovial fluid and subsequent osteonecrosis. ${ }^{27,28}$ A preexisting cartilage damage may have increased permeability for the arthroscopy fluid, which might lead to subchondral edema and consequent osteonecrosis. ${ }^{25,29}$ In the same way, inadvertent contact of the arthroscopic instruments with the femoral condyle during meniscectomy may result in iatrogenic chondral damage, predisposing to ONPK. ${ }^{30}$

Aggressive postoperative rehabilitation may contribute to the development of ONPK. It is possible that if aggressive therapy is resumed prior to bony remodeling in response to the altered load distribution that occurs postmeniscectomy, insufficiency fractures may develop.

Other authors have described the lesion as being in fact a subchondral fracture, and not pure osteonecrosis as traditionally described. ${ }^{31,32}$ The arthroscopic procedure itself was discussed as a cause of osteonecrosis. ${ }^{21,25}$ In addition, the meniscal tear itself should be a cause of osteonecrosis without arthroscopic surgery, especially in patient older than 60 years. ${ }^{11,33}$ Other causes such as the use of an irrigation pump or tourniquet did not show an association with ONPK. ${ }^{11,19,20}$

Other studies investigated the role of RFs procedures in the occurrence of ONPK. ${ }^{29,34,35}$ The heat effect on the fluid medium and the direct transfer of energy to subchondral bone were thought to be the explanatory mechanism of ONPK after RF treatment. ${ }^{34,36-41}$ Nevertheless, other studies did not confirm this hypothesis, and also found that RF chondroplasty resulted in a decrease in the number of patients developing ONPK. ${ }^{36,42,43}$ They suggested that RF chondroplasty can be safely used for shrinking, smoothing of the joint surface, sealing, and debridement by controlled application of heat for the treatment of grades II and III chondromalacia. ${ }^{44}$ Compared with mechanical shaving, RF debridement resulted in less chondrocyte death, ${ }^{45}$ shortened operative time, ${ }^{40,46}$ and created a smooth joint surface preventing irregular surface contact, with patients reporting fewer clinical symptoms in the postoperative period. On the contrary, mechanical shavers result in a 300- to $800-\mu \mathrm{m}$ chondrocyte loss due to tissue removal, with the cartilage layer still remaining rough. ${ }^{36}$

Some studies did not demonstrate significant chondrocyte death after RF treatment. ${ }^{45,47}$ Others demonstrated chondrocyte termination extending in to the treatment area despite a well-controlled debridement. ${ }^{48,49}$ According to Lu et al, ${ }^{50}$ bipolar RF systems penetrates to 78 to $92 \%$ of the total depth of the cartilage, and causes more chondrocyte death and a larger thermal lesion than the monopolar systems. The majority of studies concluded that the relation between RF and ONPK is not meaningful, while meniscal tears and partial meniscectomy are thought to be the major responsible of ONPK. ${ }^{36}$

Osteonecrosis lesions have also been noted following other arthroscopic procedures including anterior cruciate ligament reconstruction. ${ }^{51-53}$ 


\section{Diagnosis}

MRI obtained in the early stages of ONPK will demonstrate a nonspecific, large area of bone marrow edema (BME) in the femoral condyle, ipsilateral to the prior meniscectomy with heterogenous signal present on T2 imaging (-Fig. 2). By 3 months postoperatively, the extent of edema typically decreases and MRI findings in cases of ONPK are similar to those seen in cases of SPONK with T1 imaging showing a discrete low signal area surrounded by an area of intermediate signal intensity. A line of low signal is often present at the margin of the lesion, delineating the necrotic area from the adjacent area of BME. T2 images will typically show a high signal intensity at lesion edge in the region of the BME (-Fig. 3). As the lesion progresses to its final stages, bone sequestration may be present with a surrounding high signal rim along with condylar flattening and the possibility of loose body development. ${ }^{54}$

In cases of persisting or worsening pain after knee arthroscopy, the surgeon must distinguish among a preexisting SPONK, ONPK, transient BME, and a recurrent meniscal tear.

To establish the diagnosis of ONPK, it is necessary the absence of BME on a preoperative MRI performed 4 to 6 weeks after the onset of preoperative symptoms, and its presence on the postoperative MRI. Johnson et al ${ }^{19}$ have chosen 6 weeks as the minimal time interval between the onset of symptoms and MRI examination. This "window period" was based on an animal study by Nakamura et $\mathrm{al}^{5,}{ }^{55}$ who surgically induced osteonecrosis in the femoral head in a canine model and showed that it may take up to 4 weeks between surgery and the MRI findings to become positive.

In the 47 cases collected by Pape et $\mathrm{al}^{23}$ a preoperative MRI was performed in 44 of 47 patients, but the exact onset

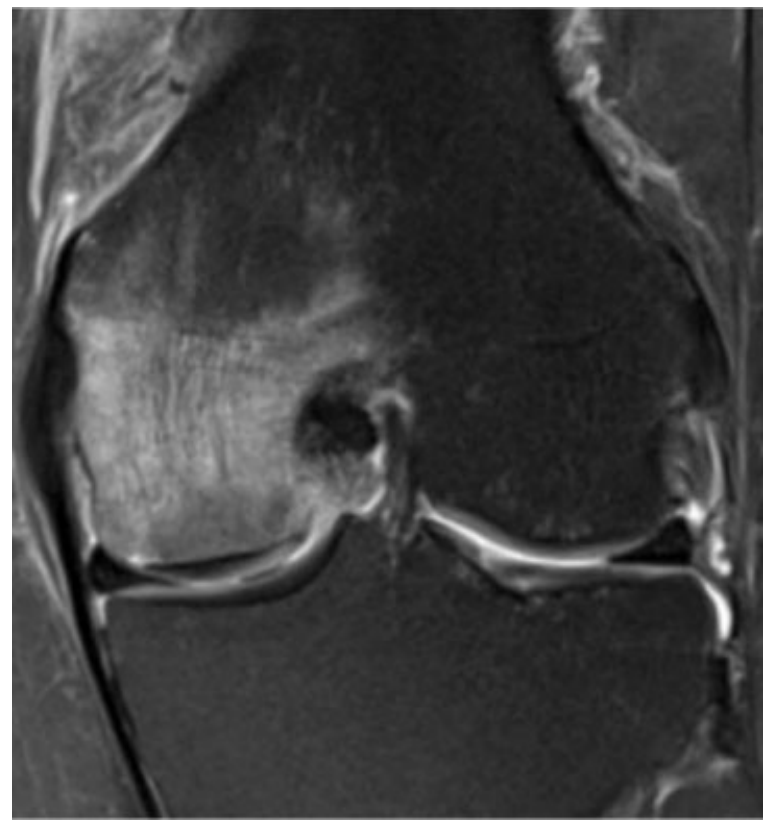

Fig. 2 Magnetic resonance imaging T2 scan showing bone marrow edema in the early phase of osteonecrosis of the medial femoral condyle.

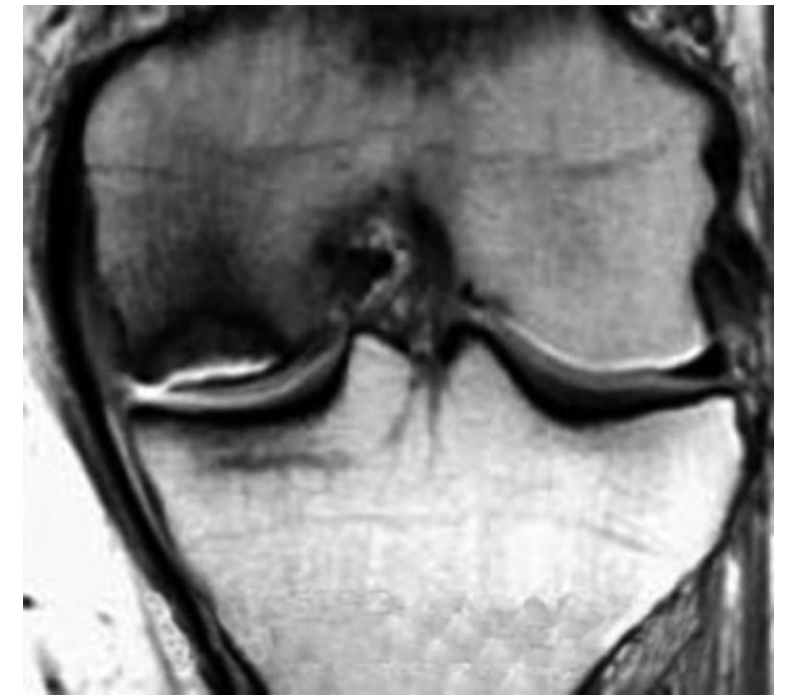

Fig. 3 Magnetic resonance imaging T1 scan showing the delineated necrotic area surrounded by bone marrow edema.

of clinical symptoms before preoperative MRI was not always mentioned. In total, up to 28 of the 47 ONPK cases (59.5\%) could represent a preexisting undiagnosed SPONK.

Kobayashi et $\mathrm{al}^{21}$ found postoperative BME on MRI in $34 \%$ of patients after partial meniscectomy within 8 months after surgery, with no preoperative signal changes. Postoperative changes were restricted to the meniscectomized compartment, both on the proximal tibia and on the distal femur. There was no correlation between the incidence or extent of BME and age, gender, or degree of chondromalacia. In addition, they did not observe progression of the disease to ONPK. ${ }^{21,56}$ Muscolo et al ${ }^{11}$ and Pruès-Latour et $\mathrm{al}^{25}$ suspected that the chance of progression to ONPK after partial meniscectomy seems to increase in patients aged older than 50 years. To assume the presence of ONPK, early-stage SPONK must have been excluded before arthroscopy, which is not a current or cost-effective standard of care. Based on the actual knowledge, a diagnostic algorithm was created and illustrated in - Fig. 4.

\section{Treatment}

Of the 47 patients diagnosed with ONPK in the review by Pape et al, ${ }^{23} 44$ (93.6\%) had either permanent MRI lesions or showed a progression to irreversible stages. In 17 of these 47 patients (36\%), further surgery was needed. Knee arthroplasty has been performed in nine, high tibial osteotomy (HTO) in two, and repeat arthroscopy in six.

It was well documented that the size of the lesion as percentage of the diameter of the medial femoral condyle is a prognostic factor and guides the treatment in SPONK. 6 , 17,57-60 In ONPK, the size of the lesion has rarely been correlated with outcome. ${ }^{23}$ It seems that even relatively small bone marrow changes on postoperative MRI may lead to osteonecrosis. Nevertheless, the treatment protocol should be uniform for SPONK and ONPK. 


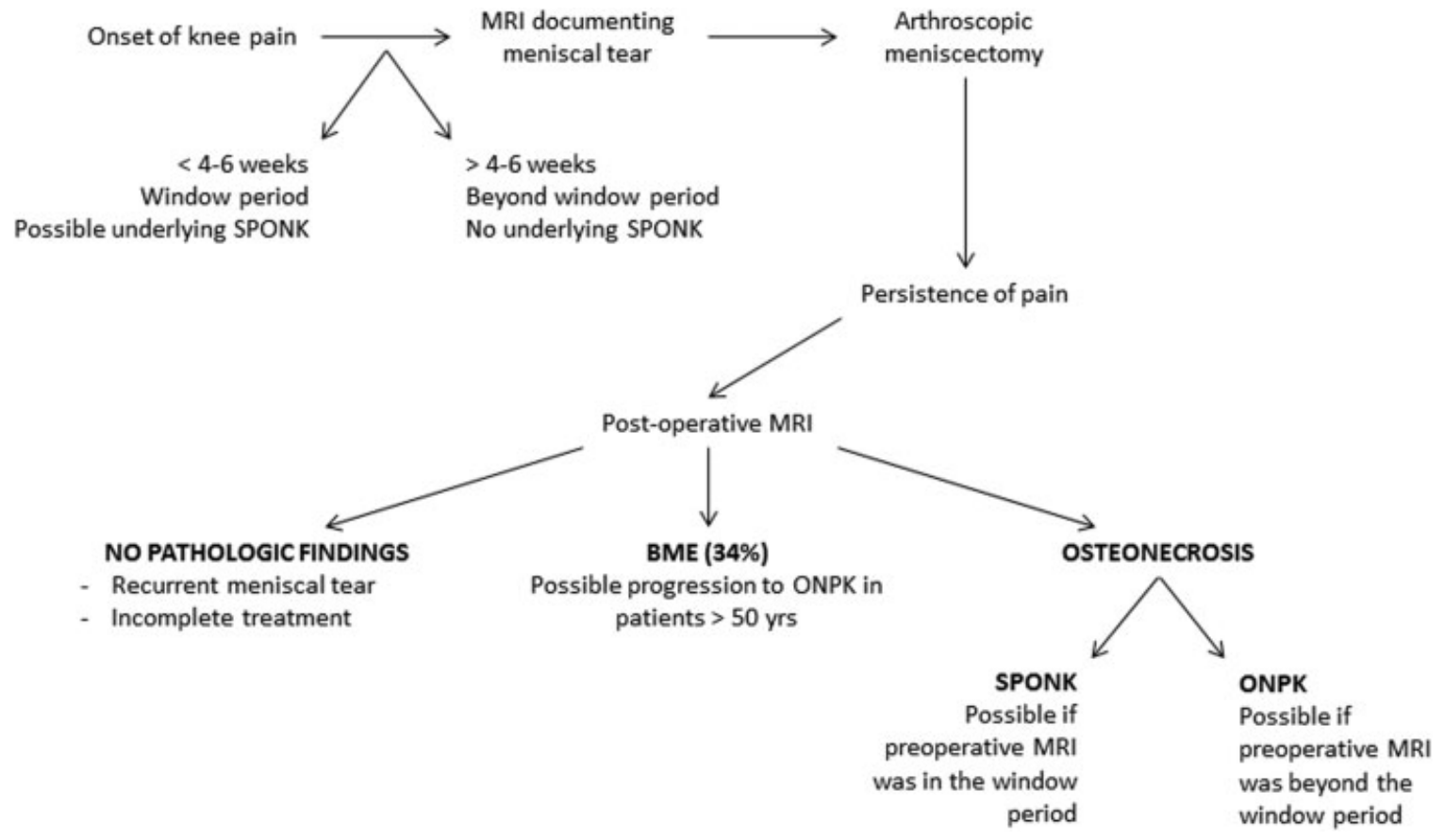

Fig. 4 Diagnostic algorithm for ONPK. BME, bone marrow edema; ONPK, osteonecrosis in the postoperative knee; MRI, magnetic resonance imaging; SPONK, spontaneous osteonecrosis of the knee.

A nonsurgical treatment protocol is recommended and more prudent than quickly performing another surgical intervention with the potential for accelerated joint destruction. ${ }^{23}$ Protected weight bearing with crutches for a 4- to 8week period is recommended, coupled with nonsteroid antiinflammatory medications. As the symptoms improve, gradual resumption of normal activities is allowed, in conjunction with physical therapies. An $89 \%$ success rate was reported with conservative management of grade ISPONK. ${ }^{57}$ In contrast to SPONK, the nonoperative treatment of ONPK is less successful, with only 3 of 47 cases improving in the series of Pape et al. ${ }^{23}$

Bisphosphonates showed to be beneficial in the nonsurgical management of both SPONK ${ }^{61}$ and ONPK, ${ }^{62}$ by preventing resorption of the necrotic region. ${ }^{63}$ These data were not confirmed by other studies. ${ }^{64}$ Available medical treatments also include vasodilators, statins, and anticoagulants. Pulsed electromagnetic fields therapy demonstrated an improvement in pain and a reduction of the necrotic area at MRI in early-stage SPONK. ${ }^{65}$

The use of the hyperbaric chamber in the treatment of SPONK for young patients was described, ${ }^{66}$ even if further reports and studies are needed to demonstrate the validity of this treatment.

Surgical management should be considered when patients do not improve clinically or radiographically after 3 months of nonoperative treatment, as well as in patients who present with osteonecrotic lesions larger than $5 \mathrm{~cm}$. ${ }^{6,17}$

Joint-preserving surgical techniques may successfully postpone the need for joint arthroplasty. ${ }^{67}$ The use of arthroscopic debridement in the management of SPONK and ONPK has limited applications. As the primary pathology is intraosseous, arthroscopic debridement has little likeli- hood of altering the course of the disease process; however, it may lead to symptomatic improvement when mechanical symptoms are present due to unstable chondral fragments or loose bodies. While retrograde drilling or microfractures may stimulate revascularization within the lesion, the potential for damage to the intact articular surface and the difficulty associated with accurately localizing the focus of the lesion makes antegrade drilling or core decompression more attractive treatment options.

Core decompression ( - Fig. 5), first described by Jacobs et $a l,{ }^{68}$ demonstrated successful healing and pain relief in

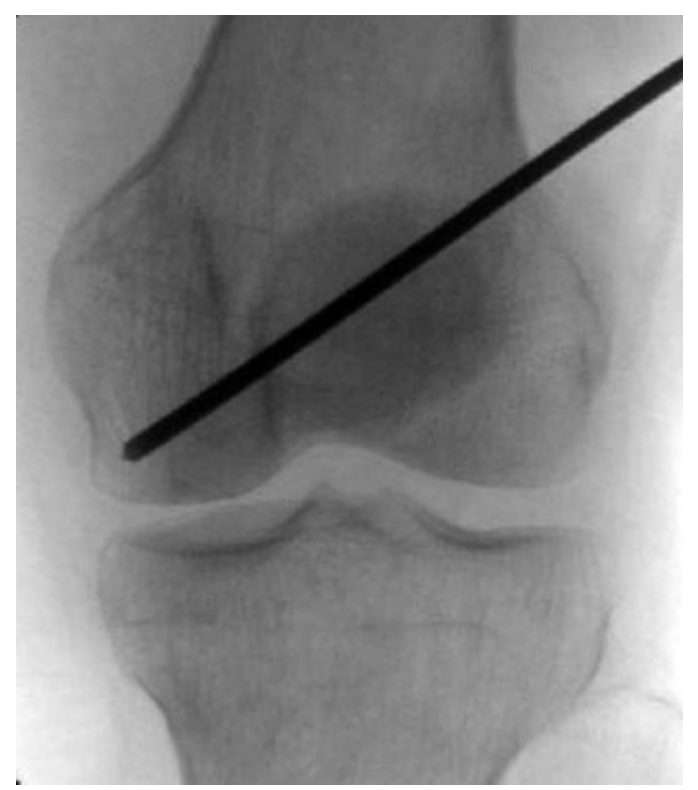

Fig. 5 X-rays showing a core decompression procedure in for osteonecrosis of the medial femoral condyle. 


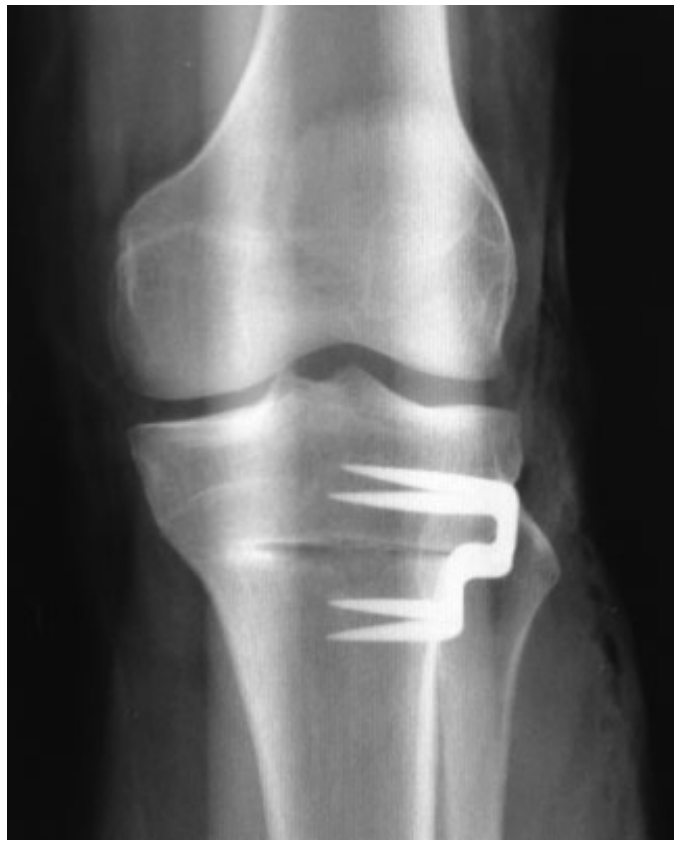

Fig. 6 Osteonecrosis of the medial femoral condyle treated by high tibial osteotomy.

stages I and II SPONK. ${ }^{69}$ Bone grafting could be associated with decompression, using autogenic or allogenic cancellous bone or demineralized bone matrix. ${ }^{70,71}$

Joint-preserving techniques include HTO, which may also be considered in young, active individuals who have failed core decompression and still have early-stage disease. HTO can offload the affected femoral condyle by shifting the weight-bearing axis laterally (-Fig. 6). HTO demonstrated better improvement of symptoms and MRI features of the lesions, compared with nonoperative treatment. ${ }^{72}$

However, patients who have progressed to subchondral collapse may benefit more from osteochondral autograft due to restoration of the cartilage surface. ${ }^{67,73}$
Osteochondral allograft transplantation is useful even in large or complex lesions, and has the advantage of restoring mature hyaline cartilage to the affected area. ${ }^{74}$

For patients in whom joint-preserving treatments fail to provide symptomatic improvement and in those with large or advanced lesions, knee arthroplasty is the treatment of choice. Depending on patient factors, lesion characteristics, and the condition of the remainder of the joint, unicompartmental arthroplasty or standard TKA may be utilized. A treatment protocol for ONPK is outlined in - Fig. $\mathbf{7}$.

\section{Conclusion}

ONPK is a rare form of osteonecrosis that often comes unexpected for both the patient and the surgeon. Its knowledge is important for the arthroscopic surgeons, given the number of knee arthroscopies worldwide performed.

In the case of ONPK, the surgeon might be involved in medicolegal sequelae. However, many authors agree that both SPONK and ONPK represent unpreventable and unpredictable conditions. Also, the diagnosis of ONPK is not always sure, as it is not possible to exclude a preexisting SPONK if the preoperative MRI was performed in the so-called window period. An original diagnostic algorithm has been described to assist the surgeon to orientate in the ONPK diagnosis. Basically, it is important to know that elderly patients with meniscal tears and chondral lesions should be alerted that there is a rare risk of osteonecrosis developing after knee arthroscopy. ${ }^{19}$ The meniscal tear itself may be a cause of osteonecrosis, especially in patient older than 60 years. ${ }^{11}$ The majority of studies agree that risk factors exist for the development of ONPK, but a certain causal relationship with arthroscopy is lacking. ${ }^{21,25,75}$

The prognosis and treatment of ONPK are not in relation to the size of the lesions, but rather to the timing of the diagnosis. An early diagnosis is required to have chances of success with conservative treatment. The latter is always indicated as first treatment. If, however, more than 6 months

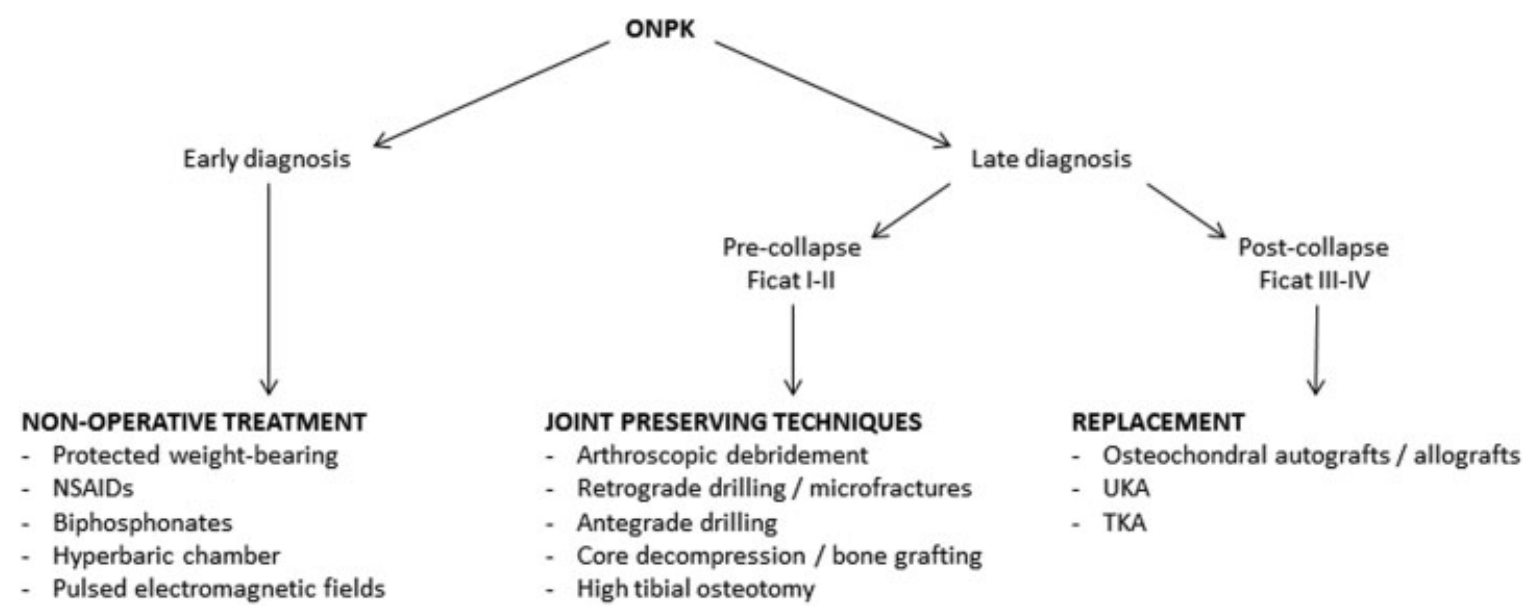

Fig. 7 Treatment algorithm for ONPK. NSAIDS, nonsteroidal anti-inflammatory drugs; ONPK, osteonecrosis in the postoperative knee; TKA, total knee arthroplasty; UKA, unicompartmental knee arthroplasty. 
from the previous intervention have passed, surgical treatment can be considered directly, depending on the degree of the lesion as for SPONK. On the basis of current knowledge, an original treatment algorithm of ONPK has been described, inspired by the treatment for SPONK, but differing in the indications, which are not dictated by the size of the lesion, that in case of ONPK have not demonstrated prognostic value, but by the timing of treatment.

\section{Conflict of Interest}

None.

\section{References}

1 Ahlbäck S, Bauer GC, Bohne WH. Spontaneous osteonecrosis of the knee. Arthritis Rheum 1968;11(06):705-733

2 Mont MA, Baumgarten KM, Rifai A, Bluemke DA, Jones LC, Hungerford DS. Atraumatic osteonecrosis of the knee. J Bone Joint Surg Am 2000;82(09):1279-1290

3 Pape D, Seil R, Fritsch E, Rupp S, Kohn D. Prevalence of spontaneous osteonecrosis of the medial femoral condyle in elderly patients. Knee Surg Sports Traumatol Arthrosc 2002;10(04): 233-240

4 Mears SC, McCarthy EF, Jones LC, Hungerford DS, Mont MA. Characterization and pathological characteristics of spontaneous osteonecrosis of the knee. Iowa Orthop J 2009;29:38-42

5 al-Rowaih A, Björkengren A, Egund N, Lindstrand A, Wingstrand H, Thorngren KG. Size of osteonecrosis of the knee. Clin Orthop Relat Res 1993;(287):68-75

6 Mont MA, Marker DR, Zywiel MG, Carrino JA. Osteonecrosis of the knee and related conditions. J Am Acad Orthop Surg 2011;19(08): 482-494

7 Reddy AS, Frederick RW. Evaluation of the intraosseous and extraosseous blood supply to the distal femoral condyles. Am J Sports Med 1998;26(03):415-419

8 Yamamoto T, Bullough PG. Spontaneous osteonecrosis of the knee: the result of subchondral insufficiency fracture. J Bone Joint Surg Am 2000;82(06):858-866

9 Akamatsu Y, Mitsugi N, Hayashi T, Kobayashi H, Saito T. Low bone mineral density is associated with the onset of spontaneous osteonecrosis of the knee. Acta Orthop 2012;83(03):249-255

10 Norman A, Baker ND. Spontaneous osteonecrosis of the knee and medial meniscal tears. Radiology 1978;129(03):653-656

11 Muscolo DL, Costa-Paz M, Ayerza M, Makino A. Medial meniscal tears and spontaneous osteonecrosis of the knee. Arthroscopy 2006;22(04):457-460

12 Robertson DD, Armfield DR, Towers JD, Irrgang JJ, Maloney WJ, Harner CD. Meniscal root injury and spontaneous osteonecrosis of the knee: an observation.J Bone Joint Surg Br 2009;91(02):190-195

13 Houpt JB, Pritzker KP, Alpert B, Greyson ND, Gross AE. Natural history of spontaneous osteonecrosis of the knee (SONK): a review. Semin Arthritis Rheum 1983;13(02):212-227

14 Fotiadou A, Karantanas A. Acute nontraumatic adult knee pain: the role of MR imaging. Radiol Med (Torino) 2009;114(03): 437-447

15 Koshino T, Okamoto R, Takamura K, Tsuchiya K. Arthroscopy in spontaneous osteonecrosis of the knee. Orthop Clin North Am 1979;10(03):609-618

16 Ficat RP. Idiopathic bone necrosis of the femoral head. Early diagnosis and treatment. J Bone Joint Surg Br 1985;67(01):3-9

17 Aglietti P, Insall JN, Buzzi R, Deschamps G. Idiopathic osteonecrosis of the knee. Aetiology, prognosis and treatment. J Bone Joint Surg Br 1983;65(05):588-597

18 Brahme SK, Fox JM, Ferkel RD, Friedman MJ, Flannigan BD, Resnick DL. Osteonecrosis of the knee after arthroscopic surgery: diagnosis with MR imaging. Radiology 1991;178(03):851-853
19 Johnson TC, Evans JA, Gilley JA, DeLee JC. Osteonecrosis of the knee after arthroscopic surgery for meniscal tears and chondral lesions. Arthroscopy 2000;16(03):254-261

20 Faletti C, Robba T, de Petro P. Postmeniscectomy osteonecrosis. Arthroscopy 2002;18(01):91-94

21 Kobayashi Y, Kimura M, Higuchi H, Terauchi M, Shirakura K, Takagishi K. Juxta-articular bone marrow signal changes on magnetic resonance imaging following arthroscopic meniscectomy. Arthroscopy 2002;18(03):238-245

22 Patel DV, Breazeale NM, Behr CT, Warren RF, Wickiewicz TL, O'Brien SJ. Osteonecrosis of the knee: current clinical concepts. Knee Surg Sports Traumatol Arthrosc 1998;6(01):2-11

23 Pape D, Seil R, Anagnostakos K, Kohn D. Postarthroscopic osteonecrosis of the knee. Arthroscopy 2007;23(04):428-438

24 Santori N, Condello V, Adriani E, Mariani PP. Osteonecrosis after arthroscopic medial meniscectomy. Arthroscopy 1995;11(02): 220-224

25 Pruès-Latour V, Bonvin JC, Fritschy D. Nine cases of osteonecrosis in elderly patients following arthroscopic meniscectomy. Knee Surg Sports Traumatol Arthrosc 1998;6(03):142-147

26 Yao L, Stanczak J, Boutin RD. Presumptive subarticular stress reactions of the knee: MRI detection and association with meniscal tear patterns. Skeletal Radiol 2004;33(05):260-264

27 Fukuda Y, Takai S, Yoshino N, et al. Impact load transmission of the knee joint-influence of leg alignment and the role of meniscus and articular cartilage. Clin Biomech (Bristol, Avon) 2000;15(07):516-521

28 Jones RS, Keene GC, Learmonth DJ, et al. Direct measurement of hoop strains in the intact and torn human medial meniscus. Clin Biomech (Bristol, Avon) 1996;11(05):295-300

29 Rozbruch SR, Wickiewicz TL, DiCarlo EF, Potter HG. Osteonecrosis of the knee following arthroscopic laser meniscectomy. Arthroscopy 1996;12(02):245-250

30 Strauss EJ, Kang R, Bush-Joseph C, Bach BR Jr. The diagnosis and management of spontaneous and post-arthroscopy osteonecrosis of the knee. Bull NYU Hosp Jt Dis 2011;69(04):320-330

31 MacDessi SJ, Brophy RH, Bullough PG, Windsor RE, Sculco TP. Subchondral fracture following arthroscopic knee surgery. A series of eight cases. J Bone Joint Surg Am 2008;90(05):1007-1012

32 Hall FM. Osteonecrosis in the postoperative knee. Radiology 2005;236(01):370-371, author reply 371

33 Bauer HC, Persson PE, Nilsson OS. Tears of the medial meniscus associated with increased radionuclide activity of the proximal tibia. Report of three cases. Int Orthop 1989;13(02):153-155

34 Bonutti PM, Seyler TM, Delanois RE, McMahon M, McCarthy JC, Mont MA. Osteonecrosis of the knee after laser or radiofrequencyassisted arthroscopy: treatment with minimally invasive knee arthroplasty. J Bone Joint Surg Am 2006;88(Suppl 3):69-75

35 Encalada I, Richmond JC. Osteonecrosis after arthroscopic meniscectomy using radiofrequency. Arthroscopy 2004;20(06):632-636

36 Cetik O, Cift H, Comert B, Cirpar M. Risk of osteonecrosis of the femoral condyle after arthroscopic chondroplasty using radiofrequency: a prospective clinical series. Knee Surg Sports Traumatol Arthrosc 2009;17(01):24-29

37 Balcarek P, Kuhn A, Weigel A, et al. Impact of monopolar radiofrequency energy on subchondral bone viability. Knee Surg Sports Traumatol Arthrosc 2010;18(05):673-680

38 Kosy JD, Schranz PJ, Toms AD, Eyres KS, Mandalia VI. The use of radiofrequency energy for arthroscopic chondroplasty in the knee. Arthroscopy 2011;27(05):695-703

39 Lotto ML, Wright EJ, Appleby D, Zelicof SB, Lemos MJ, Lubowitz JH. Ex vivo comparison of mechanical versus thermal chondroplasty: assessment of tissue effect at the surgical endpoint. Arthroscopy 2008;24(04):410-415

40 Lu Y, Edwards RB III, Nho S, Cole BJ, Markel MD. Lavage solution temperature influences depth of chondrocyte death and surface contouring during thermal chondroplasty with temperaturecontrolled monopolar radiofrequency energy. Am J Sports Med 2002;30(05):667-673 
41 Muscolo DL, Costa-Paz M, Makino A, Ayerza MA. Osteonecrosis of the knee following arthroscopic meniscectomy in patients over 50-years old. Arthroscopy 1996;12(03):273-279

42 Türker M, Çetik Ö, Çırpar M, Durusoy S, Cömert B. Postarthroscopy osteonecrosis of the knee. Knee Surg Sports Traumatol Arthrosc 2015;23(01):246-250

43 Barber FA, Iwasko NG. Treatment of grade III femoral chondral lesions: mechanical chondroplasty versus monopolar radiofrequency probe. Arthroscopy 2006;22(12):1312-1317

44 Shellock FG. Radiofrequency energy induced heating of bovine articular cartilage: comparison between temperature-controlled, monopolar, and bipolar systems. Knee Surg Sports Traumatol Arthrosc 2001;9(06):392-397

45 Turner AS, Tippett JW, Powers BE, Dewell RD, Mallinckrodt CH. Radiofrequency (electrosurgical) ablation of articular cartilage: a study in sheep. Arthroscopy 1998;14(06):585-591

46 Kaplan LD, Ernsthausen JM, Bradley JP, Fu FH, Farkas DL. The thermal field of radiofrequency probes at chondroplasty settings. Arthroscopy 2003;19(06):632-640

47 Kaplan L, Uribe JW. The acute effects of radiofrequency energy in articular cartilage: an in vitro study. Arthroscopy 2000;16(01):2-5

48 Amiel D, Ball ST, Tasto JP. Chondrocyte viability and metabolic activity after treatment of bovine articular cartilage with bipolar radiofrequency: an in vitro study. Arthroscopy 2004;20(05):503-510

49 Lu Y, Edwards RB III, Kalscheur VL, Nho S, Cole BJ, Markel MD. Effect of bipolar radiofrequency energy on human articular cartilage. Comparison of confocal laser microscopy and light microscopy. Arthroscopy 2001;17(02):117-123

50 Lu Y, Edwards RB III, Cole BJ, Markel MD. Thermal chondroplasty with radiofrequency energy. An in vitro comparison of bipolar and monopolar radiofrequency devices. Am J Sports Med 2001; 29(01):42-49

51 Athanasian EA, Wickiewicz TL, Warren RF. Osteonecrosis of the femoral condyle after arthroscopic reconstruction of a cruciate ligament. Report of two cases. J Bone Joint Surg Am 1995;77(09): 1418-1422

52 Lansdown DA, Shaw J, Allen CR, Ma CB. Osteonecrosis of the knee after anterior cruciate ligament reconstruction: a report of 5 cases. Orthop J Sports Med 2015;3(03):2325967115576120

53 Shenoy PM, Shetty GM, Kim DH, Wang KH, Choi JY, Nha KW. Osteonecrosis of the lateral femoral condyle following anterior cruciate ligament reconstruction: is bone bruising a risk factor? Arch Orthop Trauma Surg 2010;130(03):413-416

54 al-Kaar M, Garcia J, Fritschy D, Bonvin JC. Aseptic osteonecrosis of the femoral condyle after meniscectomy by the arthroscopic approach [in French]. J Radiol 1997;78(04):283-288

55 Nakamura T, Matsumoto T, Nishino M, Tomita K, Kadoya M. Early magnetic resonance imaging and histologic findings in a model of femoral head necrosis. Clin Orthop Relat Res 1997;(334):68-72

56 Hofmann S, Kramer J, Vakil-Adli A, Aigner N, Breitenseher M. Painful bone marrow edema of the knee: differential diagnosis and therapeutic concepts. Orthop Clin North Am 2004;35(03): 321-333, ix

57 Lotke PA, Abend JA, Ecker ML. The treatment of osteonecrosis of the medial femoral condyle. Clin Orthop Relat Res 1982;(171): 109-116

58 Juréus J, Lindstrand A, Geijer M, Robertsson O, Tägil M. The natural course of spontaneous osteonecrosis of the knee (SPONK): a 1- to 27-year follow-up of 40 patients. Acta Orthop 2013;84(04): 410-414

59 Lecouvet FE, van de Berg BC, Maldague BE, et al. Early irreversible osteonecrosis versus transient lesions of the femoral condyles: prognostic value of subchondral bone and marrow changes on MR imaging. AJR Am J Roentgenol 1998;170(01):71-77

60 al-Rowaih A, Wingstrand H, Lindstrand A, Björkengren A, Thorngren KG, Gustafson T. Three-phase scintimetry in osteonecrosis of the knee. Acta Orthop Scand 1990;61(02):120-127

61 Jureus J, Lindstrand A, Geijer M, Roberts D, Tägil M. Treatment of spontaneous osteonecrosis of the knee (SPONK) by a bisphosphonate. Acta Orthop 2012;83(05):511-514

62 Kraenzlin ME, Graf C, Meier C, Kraenzlin C, Friedrich NF. Possible beneficial effect of bisphosphonates in osteonecrosis of the knee. Knee Surg Sports Traumatol Arthrosc 2010;18(12):1638-1644

63 Nishii T, Sugano N, Miki H, Hashimoto J, Yoshikawa H. Does alendronate prevent collapse in osteonecrosis of the femoral head? Clin Orthop Relat Res 2006;443(443):273-279

64 Meier C, Kraenzlin C, Friederich NF, et al. Effect of ibandronate on spontaneous osteonecrosis of the knee: a randomized, doubleblind, placebo-controlled trial. Osteoporos Int 2014;25(01): 359-366

65 Marcheggiani Muccioli GM, Grassi A, Setti S, et al. Conservative treatment of spontaneous osteonecrosis of the knee in the early stage: pulsed electromagnetic fields therapy. Eur J Radiol 2013; 82(03):530-537

66 Barroso GC, Fuchs T, Thiele E, Lima MN. Spontaneous osteonecrosis in an athlete's knee treated using a hyperbaric chamber: case report and review of the literature. Rev Bras Ortop 2015; 47(03):389-393

67 Duany NG, Zywiel MG, McGrath MS, et al. Joint-preserving surgical treatment of spontaneous osteonecrosis of the knee. Arch Orthop Trauma Surg 2010;130(01):11-16

68 Jacobs MA, Loeb PE, Hungerford DS. Core decompression of the distal femur for avascular necrosis of the knee. J Bone Joint Surg Br 1989;71(04):583-587

69 Forst J, Forst R, Heller KD, Adam G. Spontaneous osteonecrosis of the femoral condyle: causal treatment by early core decompression. Arch Orthop Trauma Surg 1998;117(1-2):18-22

70 Lee K, Goodman SB. Cell therapy for secondary osteonecrosis of the femoral condyles using the Cellect DBM System: a preliminary report. J Arthroplasty 2009;24(01):43-48

71 Rijnen WH, Luttjeboer JS, Schreurs BW, Gardeniers JW. Bone impaction grafting for corticosteroid-associated osteonecrosis of the knee. J Bone Joint Surg Am 2006;88(Suppl 3):62-68

72 Marti CB, Rodriguez M, Zanetti M, Romero J. Spontaneous osteonecrosis of the medial compartment of the knee: a MRI follow-up after conservative and operative treatment, preliminary results. Knee Surg Sports Traumatol Arthrosc 2000;8(02):83-88

73 Tanaka Y, Mima H, Yonetani Y, Shiozaki Y, Nakamura N, Horibe S. Histological evaluation of spontaneous osteonecrosis of the medial femoral condyle and short-term clinical results of osteochondral autografting: a case series. Knee 2009;16(02):130-135

74 Bugbee W, Cavallo M, Giannini S. Osteochondral allograft transplantation in the knee. J Knee Surg 2012;25(02):109-116

75 Chambers C, Craig JG, Zvirbulis R, Nelson F. Spontaneous osteonecrosis of knee after arthroscopy is not necessarily related to the procedure. Am J Orthop 2015;44(06):E184-E189 